\title{
CIDADANIA E PARTICIPAÇÃO POLÍTICA NA ÉPOCA DA INDEPENDÊNCIA DO BRASIL
}

\author{
Lúcia Maria Bastos P. Neves*
}

\begin{abstract}
Para ditar mais uma ver [J caquim] Nabuco, de dizia no séulo 19 queescola e senzal a eram pólosqueserepdiam Hgjepodesedizer quea escola ea desigual dade serepelem São resultados de pesqui sa: a escola mahora a percepção dos di rètos aumenta osenso crítico, incentiva a participação política, malhora a qual idadedo voto. Nãofoi por acasoquechegamosaoséul o 21 cometatísticasainda vergonhosasdeanalfabetismo, sobretudo deadultos Educar o povoéperigoss. Basta educar a dite Oscolonizadoresportuguesescriaramessa rega, oscolonizadoresintemosa consolidaram
\end{abstract}

RESUMO: O presente artigo pretende analisar a conjuntura da Independência do Brasil enquanto uma tentativa de implantar novas idéias e práticas políticas quanto ao relaciona mento do indivíduo e da sociedade com o Estado, tendo como fontes principai s os escritos de circunstância, ou seja, os periódicos e os panfletos políticos. Nesse sentido, tais novidades poderiam ter resultado na constituição de uma autêntica esfera pública de poder, mas acabaram limi tadas e reorientadas em função das circunstâncias da época, impedindo que se criasse uma verdadeira noção de cidadania no país. Verifica-se, portanto, que cidadania e partici pação política em uma esfera verdadeiramente pública de poder são processos de construção lenta, ai nda mais em paí ses como o Brasil, envolvido desde seus inícios pela exclusão que a grande propriedade e a escravidão asseguraram.

Palavras chave Cidadania. Independência do Brasil. Práticas políticas. Panfletos. Imprensa.

* Departamento de História da Universidade Estadual do Rio de Janeiro (UERJ). 
Citizenship AND POLITICAL PARTICIPATIONAT THE

TIME OF BRAZILIAN INDEPENDENCE

ABSTRACT: Relying on periodicals and political tracts as its main sources, this paper intends to analyze the period of Brazilian Independence as an endeavor to establish new ideas and political practices regarding the reationship between individuals and both society and the State However, this drive toward an authentically public political sphere was cut short by circumstances, which hindered the constitution of a true notion of citizenship. If citizenship and political participation do take a long time to mature in a really public political sphere, this time is even longer in such countries as Brazil, ridden almost from the start by the exdusion brought about by large landholdings and slavery.

Key words Citizenship. Brazilian independence Political practices. Political tracts. Press.

stas palavras de José M urilo de Carvalho, em uma recente entrevista (2001), lembram o peso fundamental do passado his tórico. Se resgatálo, em alguns casos, para justificar a impotência no presente, como ele também aponta, pode significar apenas uma modalidade de conivência, em outros, pode representar, quando o olhar é crítico, a possibilidade de revelar mecanismos que marcaram a sociedade brasileira por séculos. Afinal, vivemos num país com uma enorme dificuldade de se construir por meio da cultura, porque a educação, como ressaltado, foi quase sempre considerada uma atividade acessória, destinada unicamente a fornecer o ornamento necessário para distinguir uma minúscula elite da enorme massa de destituídos. Cidadania e participação política em uma effera verdadeiramente pública de poder são processos de construção lenta, ainda mais no Brasil, herdeiro de cinco séculos de latifúndio e de quase outro tanto de escravidão.

Pensar e repensar a história - e também ensinála como um exercício de reflexão e de crítica - constitui por conseguinte uma atividade fundamental. Se a história consiste, como quer Duby (1980), no estabelecimento de correlações, ensinála implica despertar o aluno para a percepção do presente como o intercruzamento de durações diferenciadas, ampliando a leitura do universo social para além dos fatos mais imediatos do cotidiano. Para fazêlo, nada melhor que reconsiderar aque les episódios auja interpretação se cristalizou com o tempo, sob a forma de visões ettereotipadas, construídas em outros momentos, para a đtender a outros interesses Como ocorreu com a Independência de 1822. 
Sob esta ótica, as linhas a seguir procuram analisar a conjuntura da Independência do Brasil como uma tentativa de implantar novas idéias e práticas políticas quanto ao relacionamento do indivíduo e da sociedade com o Estado, por intermédio da imprensa, que poderiam ter resultado na constituição de uma autêntica esfera pública de poder, mas que acabaram limitadas e reorientadas em função das circunstâncias da época, impedindo que se criasse uma verdadeira noção de cidadania no país.

Por efeito da chamada Revolução do Porto de 1820, o movimento, no Rio de Janeiro de 26 de fevereiro de 1821, assim como outros semelhantes em algumas províncias, colocou em circulação, de maneira inédita no Brasil, idéias liberais e constitucionais, que logo foram divul gadas por méo de uma espantosa quantidade de jornais e panfletos. Alguns chegavam de Lisboa, outros passaram a imprimir-se no Rio de Janeiro e na Bahia, gerando um intenso debate também no Pará, no Maranhão, em Pernambuco e em outros locais de menor expressão. A multiplicação desses impressos refletia uma preocupação coletiva até então inexistente em relação ao político, pas sando seus conteúdos, como indicam as inumeráveis cartas de particulares que os redatores dos periódicos divulgavam semanalmente, a serem discutidos nas ruas e, sobretudo, nos novos espaços de sociabilidade, que cafés, academias, livrarias e sociedades secretas, como a maçonaria, tinham passado a constituir. De caráter didático e polêmico, os panfletos mantinham-se anônimos por causa da censura, mas, escritos sob a forma de comentários aos fatos recentes, ou de discussões sobre as grandes questões do momento, traduziam em linguagem acessivel os temas fundamentais do constitucionalismo, que constituíam a principal bandeira do momento. Literatura de circunstância por excelência, essas obras cumpriam o papel de levar notícias e informações a uma platéia mais ampla, que déxava de vêlas como meras novidades do domínio privado para encarálas como parte de um espaço comum. Esboçavarse, assim, a formação de uma autêntica esfera pública de poder, no sentido de Habermas (1984).

A expansão do periodismo no mundo luso-brasileiro em 1821, - seu ano áureo, pode ser considerada semelhante àquela a que a França assistiu no período da Revolução de 1789, quando, de ape nas um periódico dedicado aos assuntos culturais, passou-se, somente em Paris, para mais de 184. Em Portugal, naquele ano, surgiram cerca de 39 novos jornais, quase sempre publicados em Lisboa, Porto e Coimbra, chegando-se a afirmar, num folheto da época, que à "in- 
tentada regeneração veio unida a praga dos periódicos", reduzindose a grande arte do escritor a simplesmente "saber formar bem ou mal, tortos ou direitos, os caracteres do alfabeto" (Exorcismos..., 1821).

No Rio de Janeiro, pode ser avaliado em cerca de 20 o núme ro de periódicos que saíram à luz entre 1821-1822, cuja multiplicação levou igualmente a observações sobre a presença de uma praga periodiqueira. Começavam, em geral, como semanários, mas, com o sucesso alcançado, ampliavam a freqüência, transformando-se algumas vezes em diários, de modo a visar a uma informação de ação mais direta nos acontecimentos, por meio de um discurso muito mais ideológico e político que cultural. Embora alguns assumissem uma postura supostamente neutra, destinada a transmitir meras notícias, como o Diário do Rio de Janeiro e o Volantim, muitos acabavam por transcrever artigos publicados em outras regiões, adquirindo também um caráter político.

Constituindo uma espécie de jornal oficial, havia, naturalmente, a Gazeta do Rio de Janeiro, o primeiro periódico estampado no Brasil, a partir de 1808. Contudo, não exerceu uma influência dire ta nos acontecimentos políticos de 1821-1822, pois não participou das polêmicas, limitando-se a repetir atos oficiais, a copiar trechos das fol has européas, quando favoráveis ao governo, e a fazer inume ráveis elogios à família real. Já o Regulador Braślico-Luso (1822-1823) foi considerado a primeira folha oficiosa, no sentido de servir ao governo à custa dos cofres públicos, defendendo a união do Brasil com Portugal.

Com a proposta de realizar um periodismo de cunho mais político, O Espedho passou a ser publicado a partir de outubro de 1821, com o principal objetivo de discutir a Constituição que se estava ela borando. Fornecia ao público minuciosas informações a respeito das sessões das Cortes e relatava as notícias saídas nas gazetas portugue sas e baianas e, ainda, no Corréo Brasiliense, redigido em Londres por Hipólito José da Costa Na realidade, publicava apenas a versão oficial dos acontecimentos, evitando emitir juízos próprios, até mesmo em alguns momentos críticos, como no Dia do Fico, quando se limitou a divulgar o expediente oficial.

Em dezembro de 1821, surgiu A Malagueta, do português Luís Augusto May, considerado um dos grandes polemistas da independência, que consistia num único grande artigo do redator, e que se 
manteve, de forma descontínua, até 1832. Em seu primeiro núme ro, ele dedarava não ser "constitucional por contrato, nem corcunda [isto é, absolutista] por indinação, nem republicano, porque já não há gregos, nem romanos" e afirmava ter sido educado "à sombra da Magna Carta e do Bill dos Direitos do Homem".

De setembro de 1821 a outubro de 1822, ainda mais conhe cido e influentefoi o Revérbero Constitudional Fluminense Escrito por "dois brasileiros Amigos da Nação e da Pátria", Joaquim Gonçalves Ledo e Januário da Cunha Barbosa, o qual tinha cunho essencialmente político e servia de porta-voz para uma das principais correntes políticas do período, que defendia um liberalismo mais radical. Não obstante, a sua grande preocupação era a de fornecer "algumas idéias que dirijam e instruam o povo sobre a grande questão que hoje se agita e que se fez o mais caro desejo dos Brasileiros", que entendia como sendo uma constituição liberal.

Iniciado em 1822, o Correjo do Rio de Janeiro, cujo redator era o português J oão Soares Lisboa, adotou posturas ainda mais ra dicais e democratas. Além de um artigo, em geral polêmico, do re dator, incluía uma grande correspondência, publicava resumos dos trabalhos das Cortes e freqüentemente atacava os jornais baianos, fa voráveis ao Congresso português. Propunha-se também a esclarecer os concidadãos do Brasil e a divulgar todas as injustiças ou despotismos das autoridades, com o objęivo de se coibir tais abusos, as sim como tudo quanto fizessem as mesmas autoridades em favor da regeneração política ou da boa administração da justiça

De duração mais efêmera, mas de grande interesse sob o aspecto político, foram alguns outros, como o Papagaio, mais moderado, com a proposta ilustrada, dotada de curiosa ressonância contemporânea, de defender o direito do Brasil de aspirar ao "desejo inalienável de ser feliz"; o Constitudional; o Brasil; e o Macaco, que se apresentava, por meio de uma certa linguagem jocosa, como um defensor dos "Direitos do Brasil", querendo "União, União, União", mas "nada de dependência e servilismo".

Embora menos estudado, o periodismo também se mostrou relevante nas províncias. Na Bahia, o segundo maior centro irradia dor dessas novidades, a maioria dos jornais adotou uma postura constitucionalista e defendeu a fidelidade às Cortes de Lisboa, como - I dade d'Ouro, publicado desde 1811, e o Semanário Cívico, que pretendia instruir os cidadãos, recorrendo a uma das formas mais 
comuns da época: o catecismo político. Os jornais menores, como o Analisador Constitucional, o Espreitador Constitudional e a Abe Iha, identificavam como dever dos bons portugueses lutarem pela causa liberal e pela união de ambos os hemisférios, e jul gavam mos trarem-se inimigos da nação os que defendiam a falsa doutrina de que "Portugal quer escravizar e colonizar" o Brasil. Em oposição, havia o Diário Constitudional, depois simplesmente O Constitudional, iniciado em agosto de 1821 e cuja circulação a censura imposta pela Junta do Governo local interrompeu temporariamente em fevereiro de 1822.

Em Pernambuco, desde 1821, surgiram a Aurora Pernambucana, o Segarrega, o Maribondo, o Condiliador Nadional e a Gazeta Pernambucana, entre outros. Mais ao norte, o Conciliador do Maranhão teve início como uma gazeta manuscrita, divulgada regularmente por sete meses, mas que, em abril de 1821, passou a ser impresso e prosseguiu em atividade até julho de 1823, quando da adesão da província à causa da independência Defendia a união de Portugal com o Brasil e, em seu primeiro número impresso, de 15 de abril de 1821, dedarava:

Os grandes acontecimentos políti cos das $\mathrm{N}$ ações, devendo al gum dia entrar nas páginas da História, preci sam ser mi nutados por testemunhas contemporâneas e desinteressadas, a fim de que a posteridadepossa avaliar o mérito, ou demérito dos seus cooperadores; (...). Eis o fima quese dirige o trabal ho dos historiadores; porém como estes, ainda mes mo sendo contemporâneos dos fatos, não podem presenciálos em todo o território da Nação, cuja história escrevem, carecem documentos mais verídicos que os de uma tradição, quase sempre suspeita; eeis um dos fins dos jornais. Outro ainda mais essencial éo deservirem demediadores entreosgovernoseospovos (...).

No Pará, Felipe Alberto Patroni passou a editar O Paraense em 1822, que, ostentando por cima do título as armas do Reino Unido, não apoiava a postura separatista da Corte fluminense e propagava os ideais liberais do vintismo, defendendo a liberdade de imprensa e opondo-se ao autoritarismo militar e à ineficiência burocrático-administrativa.

Ao lado dos jornais, os muito menos estudados panfletos cons tituíram uma outra modalidade, não menos importante, de instrumentos de divulgação da nova cultura política Assumiram várias formas. Alguns, denominados de "folhetos constitucionais" pelo livreiro Paulo Martim, no Rio de Janeiro, procuravam explicar o vocabulá 
rio político liberal, pois julgavam que a divulgação dos impressos tinha atribuído uma significação nova a todos os termos, em relação aos quais "um dicionário não nos serve para nada", devendo-se observar a conduta dos políticos para entender essa "nova linguagem". Era o caso da Constituição Explicada, que examinava o pensamento de Benjamin Constant; do Constitudional Justificado; e do Cateismo Constitudional, organizado sob a forma de perguntas e respostas. Outros preferiam a forma de diálogos, como o Diálogo entre o Corcunda Abati do e o Constitudional Exaltado e o Alfaiate Constitucional, uma conversa entre um alfaiate e seus fregueses, seguindo o modelo dás sico do famoso Spectator de Addison e Steele, publicado na Inglaterra em princípios do século XVIII. No Diálogo entre a Constituição e - Despotismo (1821), a primeira, vinda do sul da Europa, encontra se com o "famigerado despotismo", travando um duelo de palavras, que termina com a troca de insultos, separando-se os dois interlocutores, "nada satisfeitos um do outro", para dirigir-se aquele "a grandes jornadas para Laybach, onde deve assistir ao Congresso dos Ministros, e esta [a Constituição] para o Brasil, onde era há longo tempo apetecida".

Ainda de 1821 são diversas cartas escritas a amigos e compadres. Famosas são aquelas escritas pelo compadre de Belém ao redator do jornal português Astro da Lusitânia, e, pelo menos, curiosa, a Carta que em defesa dos brasileiros insultados escreve ao sa cristão de Carari o estudante constitucional, amigo do filho do compadre do Rio de Janeiro. Das cartas, passou-se a farsas em verso e a dicionários, como o Dicionário corcundativo ou explicação das phrazes dos Corcundas publicado no Rio de Janeiro, em 1821, que definia "política" da seguinte maneira: "Ciência de enganar; refinada ve Ihacaria; sistema de tramóias, inventado e propagado na Europa no tempo de Luís XIV e levado à perfeição no tempo de Napoleão Bonaparte".

Finalmente, a preocupação de atingir um público mais amplo, divulgando ensinamentos sobre a Constituição, levou ao antigo costume de parodiar orações religiosas. Um exemplo pode ser encontrado no folheto A regeneração constitudional ou a guerra e disputa entre os Carcundas [sic] e Constitudionais (1821). Para narrar os acontecimentos da Revolução de 1820, o autor descreve a disputa entre os dois partidos opostos, que se encerra com o reconhecimento dos próprios erros, por parte dos primeiros, e com a imposição de um castigo, por parte dos segundos. Os corcundas deviam apresentar-se pe 
rante o Congresso Nacional e recitar em voz alta e dara várias ora ções constitucionais, como o Credo Constitucional:

Creio no Rei, o Senhor d. J oão VI, no Congresso Nacional, criador da Constituição, no Senhor d. Pedro, PríncipeLed, primogênito eherdeiro dostronos, o qual foi concebido por obra egraça de seus Augustos Pais, nasceu de sua Augusta Mãe, a Rainha d. CarlotaJ oaquina padeceu sob o poder dos ministros evalidos; em 26 defeveréro desceu ao Rocio para jurar a Constituição por si e seu Augusto Pai; em 22 de abril foi feito regente para premiar os bons, castigar os maus, efazer justiça aos corcundas, pançosecaranguejos. Creio no Congresso Nacional, ema Nação portuguesa, na comunicação dos sábios, na remi ssão dos abusos, na ressurreição da virtude da justiça, na conservação daliberdade, segurança e propriedadeena felicidadeda nação. Amém.

Todos esses periódicos, folhetos e panfletos revelavam, portanto, o ideário político traduzido de algumas idéias ilustradas do sé culo XVIII. Elaborados por indivíduos que pertenciam às elites intelectuais, destinavam-se a um público leitor que devia ser capaz não só de ler essas publicações, mas também de extrair delas um significado. Como argumenta Roberto Darnton, em O bejjo de Lamourette (1990), no entanto, "a leitura não é simplesmente uma habilidade, e sim uma maneira de fazer sentido que deve variar de cultura para cultura". Quem eram, por conseguinte, esses leitores?

Em primeiro lugar, o potencial de leitura está, evidentemente, relacionado ao número de habitantes. Apesar da precariedade dos dados, podese, no entanto, avaliar a população livre do Brasil, em 1823, a partir de uma Memória Estatística do Império, em torno de 2 milhões e 810 mil homens livres, dos quais, em 1821, cerca de 43 mil residiam na cidade do Rio de Janeiro.

A simples dimensão demográfica, porém, não é suficiente para avaliar o público com que as discussões de 1821-1823 contaram. Torna-se necessário, ainda, verificar o grau de alfabetização da população e a distribuição social desta aptidão, uma vę que a leitura exige a disponibilidade física do texto por compra ou empréstimo. Implica, também, a decifração de signos, que só o convívio com os conceitos de uma tradição cultural pode possibilitar. No Brasil, no entanto, em inícios do oitocentos, a educação estava longe de de sempenhar o papel que iria adquirir mais tarde, ao menos na Europa, como um elemento de controle social em relação às camadas mais baixas. Ao contrário, servia às elites como uma espécie de ornamento a fim de distingui-la da massa, ao mesmo tempo em que meca 
nismos tradicionais de controle funcionavam para manter o status quo vigente, como demonstra a própria escravidão.

Para o início do século XIX, não há dados oficiais sobre o número de pessoas alfabetizadas no Brasil. Alguns caminhos indiretos, no entanto, podem dar pistas. O historiador Roderick Barman (1988), por exemplo, adotou um procedimento interessante ao ana lisar o Manifesto do Fico, em fins de 1821. Partindo de um total de 43.139 habitantes livres para a cidade do Rio, ele deduziu um pouco mais de um terço referente aos menores de idade e, em seguida, dividiu o resultado pela metade, a fim de distinguir os sexos. Chegou, assim, a 14.380 homens adultos e livres, em relação aos quais os 8 mil assinantes do Manifesto constituem quase 56\%. Apesar das deficiências notórias do método de contagem de assinaturas, tal porcentual indica uma taxa de alfabetização bastante elevada da população masculina adulta e livre do Rio de Janeiro, equivalente àquela verificada em cidades francesas do século XVIII, como Aix-enProvence, Lyon e Caen. Evidentemente, a situação não era a mesma no restante do território, nem mesmo nas demais cidades, com a pos sível exceção de Salvador e, talvez, do Recife e de São Luís.

Outro meio indireto bastante sugestivo na tentativa de captar esse público leitor é o de proceder a uma avaliação das atividades relacionadas ao comércio de livros, sobre o qual as informações são menos escassas. Um exame cuidadoso da documentação revela que, no Rio de Janeiro, em especial após a instalação da Corte na cidade, esse comércio era bem mais intenso do que se costuma imaginar. Para os anos de 1821-1822, por meio dos anúncios na Gazeta e no Diário do Rio deJaneiro, foi possível identificar 9 livreiros especializados, além de outras 3 lojas ligadas às tipografias. Mais 11 nomes devem ser igualmente acrescentados, pois, como negociantes, vendiam, entre artigos variados, as publicações do dia. Para fins de comparação, em 1826, existiam em Buenos Aires apenas 5 livrarias.

Sob o ângulo da disponibilidade, por sua vez, esses escritos de circunstância não eram, decerto, inacessíveis a um público mais vasto quanto ao preço. Numa época em que uma empada de recheio de ave custava 100 rés; um arrátel de lingüiça, 280; um quartilho de tinta para escrever, 320; a aguardente de cana, 80 rés a garrafa; um sabão inglês, 120 rés a libra, os periódicos custavam, por número, em 1821, entre 80 e 120 rés. Os panfletos, segundo os catá logos do livreiro Paulo Martim, vendiam-se por um valor entre 80 e 320 rés. Chegava-se a afirmar na época que o povo, por faltar con- 
dição para ir ao teatro, divertia-se com os "bufões [os periodiqueiros] por pouco dinheiro".

Em contrapartida, numa sociedade ainda regida pela oralidade, não se pode ignorar que muitos tomavam conhecimento dessas novidades ouvindo leituras em voz alta e participando de conversas e de discussões sobre os acontecimentos políticos nas lojas e mesmo na praça pública, como D. Higgs (1998) demonstrou ocorrer nas boticas do Rio de Janeiro desde a década de 1790. Aliás, os informantes da Intendência da Polícia no período da independência não deixavam de notificála de que diversas obras francesas, repletas de espírito revolucionário, estavam sendo traduzidas, "para a edificação dos ignorantes". Ao substituir assim a leitura propriamente dita pela comunicação oral, não parece haver dúvida de que o público real atingido por essas idéias liberais era mais amplo do que se poderia a princípio imaginar.

De fato, permeando todo o debate sobre o liberalismo, nesse novo momento em que a política se tornava pública, evidencia-se a preocupação de formar uma opinião pública, por parte da elite intelectual, especialmente dos autores dos folhetos e jornais. Nesses escritos surgia como "dever do cidadão", isto é, daquele que escre via, "dirigir a opinião pública, e levála, como pela mão, ao verda deiro fim da felicidade social". De modo semelhante, José da Silva Lisboa, o futuro visconde de Cairu, em seu jornal O Conailiador do Reino Unido (1821), julgava ser sua obrigação "dirigir bem a opinião pública, a fim de atalhar os desacertos populares e as efervescências frenéticas", pois "os periódicos e papés avulsos" eram também "lidos sôfrega e inconsideradamente pelas dasses ínfimas".

Sem dúvida, nesse momento histórico, seria um anacronismo atribuir à idéa de opinião pública a concepção de uma pluralidade de indivíduos que se exprimem em termos de aprovação ou sustentação de uma ação, servindo de referencial a um projeto político definido, com o poder de alterar os rumos dos acontecimentos. Apesar dis so, entre 1821 e 1822, ela não podia ser ignorada Como informava o redator do Macaco Brasileiro, o príncipe D. Pedro conhecia e busca va "este termômetro", percebendo que o idolatravam pelo "calor e energia com que soube merecer o título de Perpétuo Defensor do Brasil".

De acordo com a utopia das Luzes, todo cidadão - qualidade "inseparável de todo o homem, que vem a este mundo" - devia ter acesso ao saber político para, uma vez instruído, poder representar 
adequadamente o seu papel de membro ativo da comunidade política, fosse como representante da nação, fosse como eleitor, recaindo sobre si a responsabilidade pela escolha dos membros do Poder Legislativo. Com esse espírito, tanto as primeiras eleições para os de putados brasileiros às Cortes de Lisboa quanto aquelas para a Assembléia Constituinte brasileira, embora utilizassem um método indireto, não estabeleciam censo algum, podendo ser votante todo cidadão com mais de 25 anos. Nessas condições, era a conclusão lógica, todo cidadão precisava adquirir conhecimento para bem servir à N ação. Assim sendo, o voto, direito que cada cidadão exercia individualmente, adquiriu uma importância fundamental que pode ser aquilatada pelo testemunho do compromissário da freguesia da Candelária do Rio de Janeiro, o bacharel Baślio Ferreira Goulart, ao descrever as eleições realizadas em abril de 1821, nessa cidade: "N ós não temos outra arma, senão o nosso voto: isto é, com que de fenderemos nossos direitos, nossos foros pelos nossos representantes". Num mundo que as desconhecia, as eleições revestiram-se, assim, de um significado extraordinário, absorvendo grande parte do simbolismo dos valores do homem libera.

Apesar de tudo isso, a própria organização social no Brasil, dominada pela escravidão, acabava por restringir a possibilidade de informar as camadas mais baixas da população e, sobretudo, de dotála de meios para agir em função das novas perspectivas fornecidas por esses escritos. Na realidade, o povo que participou das manifestações em prol da nova ordem constitucional, embora constituído por diversas categorias - como funcionários, pequenos comerciantes, artesãos, caixeiros e soldados rasos -, não admitia os cativos, que formavam quase um terço da população, e tendia a excluir, a não ser como massa de manobra de interesses originados em outros planos, aqueles situados nas fímbrias da sociedade $O$ redator do jornal A Malagueta, em seu primeiro número, reconhecia que seu objetivo era o de provocar a aná lise crítica e justa de todos os cidadãos, isto é, "proprieários, gentes de guerra diplomatas, legistas, comerciantes, lavradores, artistas, e de todos os que aqui compõem a grande família de homens livres". Em 1823, o mesmo redator distinguia "três castas de cidadãos e de hie rarquizs". Aos membros da família imperial e da aristocracia dos homens brancos atribuía um papel de liderança, mas reconhecia que também os homens libertos de cor eram admissíveis ao civismo. Os escravos, porém, constituíam um “Terceiro Estado", sem direito algum. Dessa forma, ainda que houvesse a preocupação de instruir o povo nas 
novas práticas políticas, com o intuito de didaticamente transformá lo em um conjunto de cidadãos, eram as elites que constituíam o público red desses jornais e folhetos e foi entre suas diversas facções que se jogaram os destinos da independência.

A consciência, porém, desse obstáculo interposto pela escravidão ao progresso da civilização, com que sonhavam os liberais, não esteve de todo ausente das preocupacões da elite Já em 1821, J osé Bonifácio de Andrade e Silva ao redigir, em sua essência, as Lembranças e apontamentos do governo provisório de São Paulo para os saus deputados embarcados para o Congresso de Lisboa, chamava a atenção para a necessidade "de legislar e dar as providências mais sábias e enérgicas" sobre duas questões fundamentais à prosperidade e conservação do reino do Brasil: a catequização geral e progressiva dos índios bravos e a melhoria "da sorte dos escravos, favorecendo a sua emancipação gradual e conversão de homens imorais e brutos em cidadãos ativos e virtuosos". "Combinar sabiamente tantos elementos discordes e contrários, e em amalgamar tantos metais diversos, para que saia um todo homogêneo e compacto, que não se esfacele ao pe queno toque de qualquer nova convulsão política", era o seu objetivo. Somente assim seria possível formar "em poucas gerações uma nação homogênea, sem o que nunca seremos verdadeiramente livres, respeitáveis e felizes". No entanto, para as elites, acima de tudo, de via preservar-se a integridade do futuro império brasileiro e, na conjuntura incerta da independência, ainda que fosse preciso conter o aumento do número de escravos, para manter a ordem e evitar tumultos sociais, isso significava a manutenção do sistema escravista.

Em contraponto, não deixa de ser interessante verificar, por fim, a situação do outro grande contingente excluído, o das mulhe res. Embora não possuíssem o direito de voto e não fossem conside radas cidadãs plenas, o novo dima gerado pelos acontecimentos de $1820 \mathrm{fez}$ com que surgisse na imprensa, de maneira um tanto surpreendente, discussões sobre os direitos políticos das mulheres, considerados até mesmo no próprio plenário das Cortes de Lisboa. Nele, Domingos Borges de Barros, deputado brasileiro pela província da Bahia, apresentou a proposta de que a mãe de seis filhos legítimos tivesse voto nas eleições e, apesar de ligar a cidadania da mulher à maternidade, não deixou de levantar outros aspectos bastante modernos para a época Recorrendo a exemplos ilustres, como Aspásia, e, não menos, Madame de Stä̈ - nome este inúmeras vezes vetado, na época, pelos censores régios - , o sexo frágil, segundo de, não apre 
sentava defeito algum que o privasse daquele direito, embora os homens, ciosos de mandar e temendo a superioridade das mulheres, preferissem conserválas na ignorância Ao contrário, as mulheres rivalizavam com os homens, ou mesmo os excediam, em talentos e em virtudes. Contudo, nem todos pensavam como de O deputado português Borges Carneiro defendeu que a proposta não fosse admitida à discussão, pois se tratava do exerćicio de um direito político, e dele são as mulheres incapazes, já que elas não têm voz na sociedade pública, posição esta que, colocada em votação, foi acatada pela maioria, como registra o Diário das Cortes

No Brasil, a participação da mulher como membro integrante da sociedade política não deixou de ficar consignada em alguns documentos, em especial, al gumas cartas de mul heres paraibanas, publicadas em 1823, no jornal Sentinela da Liberdade na Guarita de Pernambuco, de autoria de Cipriano Barata. Nele encontram-se três cartas das "matronas liberais", que agradecem o grande trabalho do redator em esclarecêlas sobre as obrigações que deveriam ter com a Pátria Consideravam-se "metade da sociedade humana" e, apesar de reconhecerem a fraqueza de seu sexo, não cediam "em valor, nem em patriotismo ao mais intrépido e guerreiro cidadão", dedarando que se encontravam "na firme resolução (se preciso for) de unidas aos nossos esposos, pais, filhos e irmãos" lançarem "mãos das armas" e fazerem "a mais cruenta guerra aos sectários do nefando despotismo". A primeira das cartas, escrita em junho de 1823, trazia cem assina turas. Seguiu-se uma outra, de Leocádia de Melo Moniz, redigida no mesmo mês, e uma terceira, com 21 assinaturas, datada de se tembro do mesmo ano. Apesar de não reivindicarem direito de voto ou participação política, depreendese dessas missivas que essas muIheres se colocavam em pé de igualdade com os homens em função de seu patriotismo e da luta pela liberdade Como afirmava "O Paraibano Constitucional", que enviava as cartas ao redator do jornal, as "heroínas do Brejo de Areia" conhediam "seus inalienáveis direitos" e estavam "resolutas a defender sua liberdade, movidas ao mesmo tempo do santo entusiasmo do amor à Pátria". Além disso, as cartas revelam igualmente que elas acompanhavam as discussões políticas da época, haja vista que a mencionada Dona Leocádia solicitava tornar-se assinante dos folhetos de Cipriano Barata, que de nominou essas mulheres "Espartanas valorosas da Parába".

Há ainda uma curiosa representação de mulheres ao Imperador Pedro I, em que pedem por seus maridos portugueses, ameaça 
dos de expulsão das terras brasileiras. Se as mulheres européas casadas com brasileiros não eram perseguidas - argumentavam -, os europeus casados com senhoras brasileiras que tivessem jurado a inde pendência tampouco deviam perder a pátria, pois, afinal, "que privilégio dever ter os homens neste caso?". Continuavam lamentando não possuírem "certos foros civis", o que era "uma moda universal" e, provavelmente, "uma tirania do sexo masculino", mas révindicavam serem reconhecidas como cidadãs efetivas, capazes de também passar pelo sangue aos maridos a nova nacionalidade

Essas atitudes originais evidenciam o quanto o período da independência foi rico em debates. Essa fermentação, no entanto, não foi suficiente para gerar uma revolução, como quis ver José H onório Rodrigues (1975-1976). Sem dúvida, os autores desses jornais e panfletos foram capazes de ver na palavra escrita uma fonte de poder capaz de produzir reformas e, ao divulgarem o ideário do liberalis mo, por meio de uma pedagogia do constitucionalismo, forjaram o separatismo que, durante o ano de 1822, levaria ao rompimento entre - Brasil e a antiga metrópole Mais importante ainda, criaram as ba ses ideológicas sobre as quais, posteriormente, iria assentar-se o novo país. Contudo, ao temerem qualquer alteração brusca da ordem social e ao fecharem os olhos para os problemas específicos da implantação do liberalismo na América portuguesa - em particular, as contradições criadas pela escravidão -, acabaram implantando um simulacro do ideário que defendiam. O resultado foi que, ao invés de dar origem à participação política e à noção de cidadania, a independência redundou num modelo de nação do qual a maioria ficou excluída, valendo a cultura política gerada pelos inúmeros textos impressos somente como um instrumento educacional da própria elite, a fim de garantir o lugar que ocuparia na estrutura de poder do futuro Império do Brasil.

No fundo, ainda que essa proposta de um Império brasileiro - decorrente de uma percepção ilustrada da realidade, que se generalizou no início do século XIX pelo mundo luso-brasileiro, em oposição à visão litúrgica característica do Antigo Regime - reconheces se na política do Estado um instrumento de ação sobre a sociedade, da não foi capaz de criar normas impessoais escritas, sob a forma de lè, que elevassem os súditos à condição de cidadãos. Ao contrário, como já assinalou, mais uma vez, José Murilo de Carvalho (1996), a cidadania no Brasil foi construída de cima para baixo, predominando a cultura política que Almond e Verba denominaram de 
súdita, quando não paroquial, em que o relacionamento dos indivíduos com o Estado, que define a cidadania, consiste na submissão passiva ao produto de decisões político-administrativas situadas em outra effera Situação paradoxal que faz com que se contraponham "a grande dependência em relação ao Estado e o extremado legalismo à atitude freqüentemente desrespeitosa e anarquizante diante do poder e das leis".

Nessa perspectiva, o liberalismo no mundo luso-brasileiro padeceu de limites profundos, estabelecidos pelas dimensões restritas da esfera política propriamente pública. A cultura política da independência implantou, sem dúvida, certas práticas fundamentais do liberalismo, capazes de converter a Coroa em Estado, ao extrair a política dos ć́rculos palacianos para situála na praça pública; ao organizar a sociedade por meio de uma Constituição, ainda que outorgada; e ao estabelecer uma divisão de poderes que definia al gum espaço para a participação dos cidadãos, como as eleições. A autêntica vida pública, porém, não foi capaz de estenderse além de uma elite, mais intelectual e política que social, sediada nas principais cidades e temerosa de afetar os interesses quase sempre mudos dos poderosos de todas as latitudes. Neste sentido, as hesitações do poder, que não conseguia substituir as velhas armas da censura e da repressão pela novidade da ideologia, e a cesura fundamental da sociedade, enraizada na visão de mundo tradicional, que distinguia livres e cativos, inviabilizaram a condução do liberalismo e da prática da cidadania às suas últimas conseqüências. Os argumentos liberais permaneceram meros artifícios retóricos, que, ao criarem a ilusão da política (Furet, 1983), possibilitaram, e continuariam possibilitando, que o mais importante ficasse subterrâneo, emperrando a formação da nação, ao legitimar o domínio tradicional de uma pequena elite e ao assegurar a exclusão dos demais.

Hoje em dia, essas contradições da sociedade brasileira de 200 anos atrás trazem novamente à tona uma série de questões que ainda assombram o país do terceiro milênio. Por isso, se o momento da construção e da consolidação da independência possibilitou as primeiras discussões sobre a concepção de um projeto de Brasil, pauta do na cultura política do liberalismo, no qual a necessidade de se construir uma consciência de cidadania não estava de todo ausente, voltar a discutir o episódio em nossas salas de aula possibilita rexaminar em suas rázes as relações dos indivíduos com o Estado e 
o poder, e permite colocar no centro de nossas atenções a preocupa ção com a cidadania. Este é o poder da história e da educação.

\section{Referênciasbibliográficas}

Fontes:

CORREI O Braziliense au Armazem Literário. (v. 1, 1808). São Paulo: Imprensa Oficia;; UNIEMP; LABJOR, 2000.

O DEBATE político no processo da independênda; introdução de Raymundo Faoro. Rio de Janeiro: Conselho Federal de Cultura, 1973.

DIÁLOGO entrea Constituição eo despotismo. Rio de Janeiro: Imprensa Nacional, 1821.

DOLHNIKOFF, M. José Bonifáaio: projetos para o Brasil. São Paulo: Companhia das Letras, 1998.

EXORCISMOS contra periódi coseautrosmalefícios Lisboa: Off. da Viúva de Lino da Silva Godinho, 1821.

GOULART, B.F. Disaurso sobreo dia 8 deabril de 1821. Rio de Janeiro: Imprensa Regia, 1821.

LEMBRANÇAS e apontamentos do governo provisorio da provinaia de S. Paulo para os seus deputados Rio de Janeiro: Imprensa Nacional, 1821.

LIMA, J.J.L. Dicionario corcundativo au explicação das phrazes dos Corandas Rio de Janeiro: Imprensa Nacional, 1821.

MEMORIA estatística do império do Brasil. Revista do Instituto Hisórico e Geogáfico Brasileiro, Rio de Janeiro, v. 91, no 58, p. 91-99, 1895.

A RENEGAÇÃO constitudional ou guerra edisputa entre os carcundas e os constitudionaes origem destes nomes e capitulação dos carcundas escripta pelo constitucional europeo ao constitudional brasileiro e offerecida a todos os verdadeiros constitucionaes [Rio de Janeiro: Imprensa Regia, 1821].

REQUERI MENTO, rasão e Justiça; representação dirigida a D. Pedro I de mulheres do Brasil. Rio de Janeiro: Imprensa Nacional, 1823. 
Livros e artigos

BARMAN, R.J. Brazil: the forging of a nation (1798-1852). Standford: Univ. Press, 1988.

CARVALHO, J.M. A escola e a desigual dade são pólos que se repelem Jarnal do Brasil, Rio de Janeiro, 10 mar. 2001, cad. Idéas.

CARVALHO, J.M. Brasil: nações imaginadas In: Carvalho, J.M. Pontos e bordados escritos de história e política. Belo Horizonte: UFMG, 1998. p. 233-268.

CARVALHO, J.M. Cidadania: tipos e peraursos. Estudos Históricos Jus tiça e Cidadania, Rio de Janéro, v. 9, № 18, p. 337-359, 1996.

COELHO, G.M. Anarquistas demagogos edissidentes a imprensa liberal no Pará de 1822. Belém: CEJUP, 1993.

DARNTON, R. O beijo de Lamourette mídia, cultura e revolução. São Paulo: Companhia das Letras, 1990.

DIAS, M.O.S. Aspectos da ilustração no Brasil. Revista do Instituto Hisó rico e Geográfico Brasilèro, Rio de Janeiro, v. 278, p.105-170, 1968.

DUBY, G.; LARDREAU, G. Dialogues Paris Flammarion, 1980.

FURET, F. Pensar a revdução francesa. Trad. de Rui Femandes de Canva Iho. Lisboa: Edições 70, 1983.

HABERMAS, J. Mudança estrutural na efera pública. Rio de Janeiro: Tempo Brasileiro, 1984.

HIGGS, D. Espaço urbano e pecado no Rio de Janeiro nos finais do século XVIII. Revista da Sociedade Brasileira de Pesquisa Histórica, Curitiba, v. 14, p. 19-31, 1998.

LUSTOSA, I. Insultos impressos a guerra dos jornalistas na independência (1821-1823). São Paulo: Companhia das Letras, 2000.

LYRA, M.L.V. Memória da Independêndia marcos erepresentações simbólicas. Revista Brasileira deHistória, São Paulo, v. 15, № 29, p.173199, 1995.

NEVES, L.M.B.P. Leitura e leitores no Brasil, 1820-1822: o esboço frustrado de uma effera pública de poder. Acervo, Rio de Janeiro, v.8, no 1-2, p. 123-138, jan/dez. 1995. 
NEVES, L.M.B.P. A “guerra das penas": os impressos políticos ea inde pendência do Brasil. Tempo, Rio de Janeiro, v.8, no 4, p. 41-65, dez. 1999.

NEVES, L.M.B.P.; MACHADO, H.F. O Império do Brasil. Rio de Ja neiro: Nova Fronteira, 1999.

RODRIGUES, J.H. A independêndia: revolução e contra revolução. Rio de Janeiro: Francisco Alves, 1975-1976. 5 v.

SOUZA, I.L.C. Pátria Corcada: o Brasil como corpo autônomo, 17801831. São Paulo: UNESP, 1999. 